\title{
Convection and Its Impact on Weather
}

\author{
Peter Bechtold (D)
}

Citation: Bechtold, P. Convection and Its Impact on Weather. Atmosphere 2021, 12, 437. https:// doi.org/10.3390/atmos12040437

Received: 25 March 2021

Accepted: 27 March 2021

Published: 29 March 2021

Publisher's Note: MDPI stays neutral with regard to jurisdictional claims in published maps and institutional affiliations.

Copyright: (C) 2021 by the author. Licensee MDPI, Basel, Switzerland. This article is an open access article distributed under the terms and conditions of the Creative Commons Attribution (CC BY) license (https:// creativecommons.org/licenses/by/ $4.0 /)$.
European Weather Centre, Reading RG29AX, UK; peter.bechtold@ecmwf.int

This Special Issue of Atmosphere is entitled "Convection and its impact on weather comprises seven original papers".

Convection affects weather on all temporal and spatial scales, from the individual convective updraught, the mesoscale convective system and the diurnal cycle of convection, up to the large-scale convectively coupled waves and the intra-seasonal oscillations. Weather and climate predictions strongly depend on the representation of the convective processes, such as net atmospheric heating and transport of mass and momentum, be it with the aid of a convective parametrization scheme or through an explicit representation, depending on the horizontal resolution of the forecast model.

It is my great pleasure to report that we have a collection of seven original papers that cover a significant part of these impact and prediction aspects. Interestingly, the common trait among these papers is the interaction of the convection with the environment and the larger-scale flow, highlighting the role of instability and moisture convergence.

The diurnal cycle of convection over Eastern Asia is discussed by Zhang et al. [1]. The climate model employed by the authors at a horizontal resolution of about $1^{\circ}$ with a classical convection parametrization produced an afternoon precipitation peak in phase with the surface heating. In contrast, the climate model with an embedded 2D cloud model at $4 \mathrm{~km}$ resolution (super-parametrization) realistically reproduced the observed early morning convection peak that is associated with long-lived mesoscale convective systems originating over steeper orography in the afternoon and propagating eastward over lower terrain. The diurnal cycle of convection is shown to be strongly modulated by the diurnal variations in the low-level moisture flux and convergence.

Staying in Asia, Huang et al. [2] and Tirkey et al. [3] also discuss the predictions of the boreal summer intra-seasonal oscillations (BSISO) and the Indian summer monsoon intra-seasonal oscillation (MISO), respectively. Both papers highlight for Taiwan and India the strong modulation of moisture flux and local rainfall by 10-60-day intra-seasonal oscillations and investigate the predictability of these large-scale oscillations and the northward propagation of the respective monsoon flow. Using state of the art global forecasting systems, Huang et al. [2] evaluate the predictability of the 30-day BSISO mode to be about 10 days. Tirkey et al. [3] note the insensitivity of the forecast results to horizontal resolution and point to the influence of model physics on the predictability, notably convection parametrization, through the vertical mixing of moisture.

On a smaller scale, ensemble predictions of a supercell thunderstorm system over Bulgaria are assessed by Chipilski et al. [4] against an extensive set of radar reflectivity and lightning observations. While the global state of the art ensemble prediction system could indicate a convective threat 4 days ahead, the convection-permitting ensemble hindcasts could reproduce strong convective updraught and detailed mesoscale structures with a $12 \mathrm{~h}$ lead. This points to the interesting problem on how to construct an optimal convection-resolving ensemble that accounts for errors in convection initiation and the diurnal cycle.

The remaining three articles cover the important subject of the interaction of the convection with the large-scale circulation. Peters et al. [5] compare for West Africa the predictions of two operational weather prediction systems at $10 \mathrm{~km}$, using convection 
parametrization, against short-range forecasts with a $2.5 \mathrm{~km}$ convection-permitting model. The convection-permitting simulations realistically represent the westward propagating, "auto-entertaining" mesoscale systems, so-called squall lines, while in the operational models, the westward propagating systems are absent under weak large-scale forcing.

Furthermore, the article by Chen and Zhang [6] examines, with the aid of cloud resolving model data from a squall line case, different convective predictors that could be used to improve the convection large-scale coupling (i.e., the convective closure) in convection parametrization schemes as highlighted in [5]. The predictors include the change in convective available potential energy (CAPE), the moisture convergence and the $500 \mathrm{hPa}$ vertical velocity. Interestingly, the correlations of these quantities with the precipitation depend on the size of the averaging domain size, which is an important aspect to consider for convection parametrization at $\mathrm{km}$-scale horizontal resolutions.

Finally, the article by Parsons et al. [7] examines the origin of large errors in Northern Hemisphere medium-range weather forecasts during spring/summer, so-called forecast busts. With the aid of wave package analyses, they could trace the forecast bust to errors in the upper-level convective outflow over Central United States, in particular when the observed convection happens in the vicinity of the upper-level jet. Therefore, improving these convection errors will greatly benefit medium-range weather forecasts.

Enjoy reading!

Funding: This research received no external funding.

Institutional Review Board Statement: Not applicable.

Informed Consent Statement: Not applicable.

Acknowledgments: The editor would like to thank the authors from China, Taiwan, India, Bulgaria, the United States of America, Germany, and the United Kingdom for their contributions to this Special Issue, and the reviewers for their constructive and insightful reviews. The editor is grateful to Alicia Wang for her kind support in processing and publishing this Special Issue.

Conflicts of Interest: The authors declare no conflict of interest.

\section{References}

1. Zhang, Y.; Chen, H.; Wang, D. Robust nocturnal and early morning summer rainfall peaks over continental East Asia in a global multiscale modeling framework. Atmosphere 2019, 10, 53. [CrossRef]

2. Huang, W.-R.; Liu, P.-Y.; Chen, J.-H.; Deng, L. Impact of boreal summer intra-seasonal oscillations on the heavy rainfall events in Taiwan during the 2017 Meiju season. Atmosphere 2019, 10, 205. [CrossRef]

3. Tirkey, S.; Mukhopadhyay, P.; Krishna, R.P.M.; Dhakate, A.; Salunke, K. Simulations of monsoon intraseasonal oscillation using climate forecasting system version 2: Insight for horizontal resolution and moist processes parametrization. Atmosphere 2019, 10, 492. [CrossRef]

4. Chipilski, H.G.; Tsonevski, I.; Georgiev, S.; Dimitrova, T.; Bocheva, L.; Wang, X. Analysis of a case of supercellular convection over Bulgaria: Observations and numerical simulations. Atmosphere 2019, 10, 486. [CrossRef]

5. Peters, K.; Hohenegger, C.; Klocke, D. Different representation of mesoscale convective systems in convection-permitting and convection-parameterizing NWP models and its implications for large-scale forecast evolution. Atmosphere 2019, 10, 503. [CrossRef]

6. Cheng, R.; Zhang, G.J. Relation convection to GCM grid-scale fields using cloud-resolving model simulation of a squall line observed during MC3E field experiment. Atmosphere 2019, 10, 523. [CrossRef]

7. Parsons, D.B.; Lillo, S.P.; Rattray, C.P.; Bechtold, P.; Rodwell, M.J.; Bruce, C.M. The role of continental mesoscale convective systems in forecast busts within global weather prediction systems. Atmosphere 2019, 10, 681. [CrossRef] 